\title{
Clinical and pathological features of primary carcinoma of the cystic duct
}

\author{
Takenari Nakata $\cdot$ Akira Kobayashi $\cdot$ Shiro Miwa \\ Junpei Soeda $\cdot$ Takeshi Uehara $\cdot$ Shinichi Miyagawa
}

Received: 4 December 2007 / Accepted: 31 January 2008/Published online: 19 December 2008

(C) Springer 2008

\begin{abstract}
Background According to Farrar's criteria, a tumor restricted to the cystic duct is defined as cystic duct carcinoma, but this definition excludes advanced carcinoma originating from the cystic duct.

Patients and methods For the purpose of this study, primary cystic duct carcinoma was defined as a tumor originating from the cystic duct. We investigated the clinicopathological features of 15 cystic duct carcinomas, including 13 that did not fit Farrar's criteria, and compared them with those of 52 cases of gallbladder carcinoma and 161 cases of extrahepatic bile duct carcinoma.

Results The incidence of primary cystic duct carcinoma was $6.6 \%$ among all malignant biliary tumors. The main symptom was jaundice in $67 \%$ of cases. The operative procedures employed ranged from cholecystectomy to hepatopancreatoduodenectomy. The cases of cystic duct carcinoma and bile duct carcinoma showed a high frequency of perineural infiltration. The overall 5-year survival rate of the 15 patients was $40 \%$.

Conclusion Patients with advanced cystic duct carcinoma show a high frequency of jaundice and perineural infiltration. Our data suggest that cystic duct carcinoma may be considered a distinct subgroup of gallbladder carcinoma. Radical surgery is necessary for potentially curative resection in patients with advanced cystic duct carcinoma.
\end{abstract}

T. Nakata $\cdot$ A. Kobayashi $\cdot$ S. Miwa $\cdot$ J. Soeda $\cdot$

S. Miyagawa $(\square)$

Department of Surgery, Shinshu University School of Medicine,

3-1-1 Asahi, Matsumoto, Nagano 390-8621, Japan

e-mail: shinichi@shinshu-u.ac.jp

T. Uehara

Department of Laboratory Medicine, Shinshu University School of Medicine, 3-1-1 Asahi, Matsumoto, Nagano 390-8621, Japan
Keywords Extrahepatic bile duct carcinoma . Gallbladder carcinoma $\cdot$ Primary cystic duct carcinoma

\section{Introduction}

Primary carcinoma of the cystic duct is rare [1-3]. Cystic duct carcinoma was defined by Farrar [1] in 1951 as (1) growth restricted to the cystic duct, (2) absence of neoplasia in the gallbladder, hepatic ducts, or common bile duct, and (3) histological confirmation of carcinoma cells in the mass. Farrar's criteria have been used without modification for 50 years and refer exclusively to "restricted" cystic duct carcinoma, thereby excluding "advanced" cystic duct carcinoma. However, because the cystic duct is a short structure, advanced carcinoma of the cystic duct can easily invade adjacent organs. Consequently, Farrar's criteria do not always facilitate a diagnosis of primary cystic duct carcinoma, particularly in advanced cases. The preoperative preparation, surgical procedure, histological features and prognosis of "advanced" cystic duct carcinoma are not well-defined.

As a tumor grows concentrically in all directions, it is acceptable to consider the center of the tumor as representing the primary site. Siewert et al. $[4,5]$ have used this concept to classify tumors located at the gastroesophageal junction, differentiating. They differentiated adenocarcinoma of the esophagogastric junction into three distinct tumor entities and stated that the assignment of a location is purely morphological and based on the anatomical location of the tumor center. Ohtani et al. [6] also defined the primary site of a tumor as the geometric center of the tumor, which lies on the longitudinal diameter of the gross tumor in surgical specimens. In an advanced tumor that has extensively invaded the surrounding structures, the site of origin is not obvious at first glance, but histological examination of serial sections of the 
resected specimen should be able to reveal the center of the tumor so that a diagnosis of cystic duct carcinoma can be established. For the purpose of the study reported here, therefore, cystic duct carcinoma was defined as a tumor whose center was located in the cystic duct, including tumors that had spread to the bile duct and/or gallbladder. It should be emphasized that such cases are excluded by Farrar's strict criteria. We investigated the clinical features, operative procedures employed, pathological findings and prognosis in 15 patients with cystic duct carcinoma. We also compared the clinicopathological findings of cystic duct carcinoma with those of gallbladder and extrahepatic bile duct carcinomas. More importantly, although cystic duct carcinoma is classified as gallbladder carcinoma by the Japanese criteria [7], our data suggest that it could be considered a distinct subgroup of gallbladder carcinoma.

\section{Patients and methods}

\section{Definition}

Cystic duct carcinoma was diagnosed when the center of the tumor mass was located in the cystic duct. Even if this possibility was suspected before surgery, the final diagnosis was always made by examination of the resected specimen. Because histopathological examination of the specimen is the diagnostic gold standard, patients in whom cystic duct carcinoma was suspected, but did not undergo resection, were not included. Tumors were classified into four types on the basis of the extent of spread: Type I, the tumor was located wholly within the cystic duct; Type II, the tumor extended to the gallbladder; Type III, the tumor extended to the common hepatic duct or the common bile duct (including extension into the lumen and external invasion to the bile duct wall); Type IV, the tumor extended to both the gallbladder and the bile duct (Fig. 1).

\section{Patients}

Between July 1990 and July 2006, cystic duct carcinoma was diagnosed in 15 patients at our medical center. Two patients had initially undergone laparotomy for acute cholecystitis at other affiliated hospitals, and the tumor in the cystic duct had been detected in the surgical specimen. These patients were then referred to our department where they underwent curative surgery. In the same period, 52 gallbladder carcinomas, 112 extrahepatic upper bile duct carcinomas and 49 lower bile duct carcinomas were resected in our hospital. The surgically resected tissue was routinely fixed in $10 \%$ formalin, embedded in paraffin, cut serially into 5 - $\mu \mathrm{m}$-thick slices, and prepared in the usual manner with hematoxylin and eosin staining.

\section{Statistical analysis}

Statistical analysis was performed using the Fisher's exact probability test. Univariate analysis to identify variables significantly related to survival was performed using the Kaplan-Meier method, and differences in survival were evaluated by the log-rank test. Statistical analysis was carried out using StatView ver. 5.0 J software (SAS Institute, Cary, NC). Differences at $P<0.05$ were considered significant.

\section{Results}

Preoperative preparation and operative procedure

The median age of the 15 patients with primary cystic duct carcinoma was $67.8 \pm 7.9$ years (range 57-81 years), and the male to female ratio of this patient cohort was 2:1 (ten men, five women). The main symptoms were abdominal pain in $66.7 \%$ of the patients and jaundice in $66.7 \%$. Ultrasonography and computed tomography were used for the initial evaluation. The gallbladder was hydropic in 14 patients (93\%), and four patients had accompanying gallstones. Twelve patients underwent endoscopic retrograde cholangiopancreatography (ERCP), which showed stenosis or obstruction of the common bile duct or the common hepatic duct in nine patients and obstruction of the cystic duct in all 12. In our study, four patients had undergone multi-detector-row computed tomography (MDCT) since

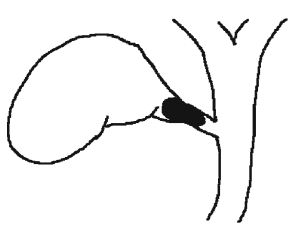

Type I

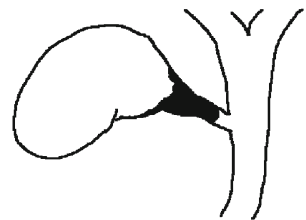

Type II

Fig. 1 Different types of primary carcinoma of the cystic duct. Type I, the lesion is located wholly within the cystic duct; Type II, the lesion extends to the gallbladder; Type III, the lesion extends to the

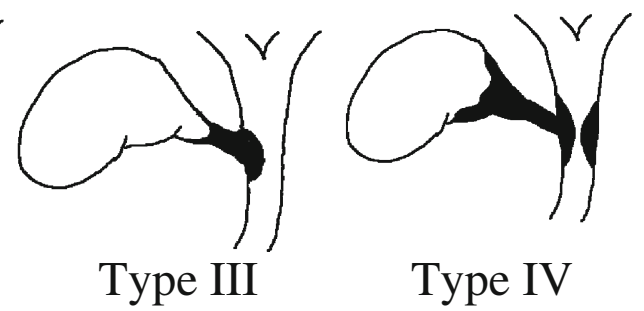

common hepatic duct or the common bile duct; Type IV, the lesion extends to both the gallbladder and the bile duct 


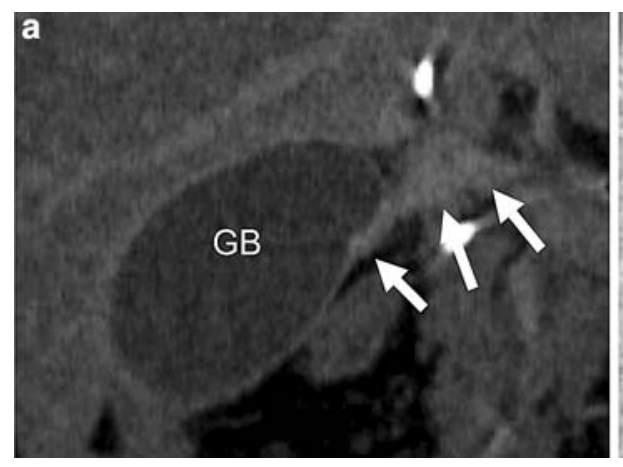

Fig. 2 a A coronal view of multi-detector-row computed tomography (MDCT) shows the location of the tumor in the cystic duct and the spread of the tumor to the gallbladder with enhancement (white

2003; based on the results observed on the MDCT scan in terms of the location of the center of the tumor mass and the extent of tumor spread, three of these four patients were preoperatively diagnosed as having primary cystic duct carcinoma (Fig. 2).

Preoperatively, acute cholecystitis was diagnosed in four patients, extrahepatic bile duct carcinoma in seven patients, gallbladder carcinoma in one patient, and primary cystic duct carcinoma in three patients (Table 1). The diagnosis of cystic duct carcinoma in two patients was based on examinations of the surgical specimen after cholecystectomy. Among the other 13 patients, cystic duct carcinoma was diagnosed intraoperatively in seven patients, and gallbladder carcinoma or bile duct carcinoma was diagnosed in six patients. Cholecystectomy and hepatoduodenal ligament skeletonization with extrahepatic bile duct resection were performed in 14 patients. The operations performed ranged from cholecystectomy without extrahepatic bile duct resection to hepatopancreatoduodenectomy (Table 2). Seven patients underwent extended right hepatectomy or hepatopancreatoduodenectomy after preoperative portal vein embolization [8]. The operative mortality rate was $0 \%$, and the overall morbidity rate was $40 \%$. Postoperative infectious complications (intraabdominal abscess, biloma) occurred in four patients: three of these had undergone extended right hepatectomy, and one had undergone hepatopancreatoduodenectomy. Pleural effusion and cardiac failure occurred in two and one patients, respectively. There were no cases of postoperative hepatic failure.

\section{Histological findings and outcome}

The median tumor size was $25 \mathrm{~mm}$ (range $4-45 \mathrm{~mm}$ ). The tumor was localized wholly within the cystic duct (Type I) in two patients, it extended into the gallbladder lumen (Type II) in four patients, it extended into the lumen of the

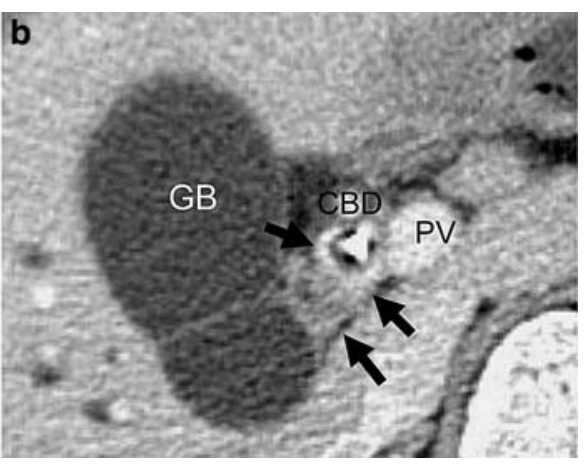

arrow). b An axial view of MDCT shows wall thickness of the cystic duct and spreading to the common bile duct with enhancement (black arrow). $G B$ Gallbladder, $C B D$ common bile duct, $P V$ portal vein

extrahepatic bile duct (Type III) in five patients, and it extended into both the gallbladder and bile ducts (Type IV) in four patients. All of the tumors were adenocarcinomas: papillary in three patients, well differentiated in six patients, moderately differentiated in one patient, and poorly differentiated in five patients. Of the 15 patients with cystic duct carcinoma, the depth of tumor invasion was limited to the fibromuscular layer in two patients; in eight and five patients, invasion was limited to the subserosa or was beyond the serosa, respectively. Infiltrating growth patterns were observed in 12 patients (Table 3). The cystic duct is adjacent to major structures such as the liver, extrahepatic bile duct and right hepatic artery; consequently, most tumors were at advanced pT stages (pT1 in two patients, $\mathrm{pT} 2$ in nine patients, pT3 in three patients, and pT4 in one patient), as categorized by the pTNM classification [9]. High frequencies of perineural invasion (11/15), lymphatic invasion (12/ $15)$, and venous invasion (10/15) were observed. Five patients $(33 \%)$ had lymph node metastasis in the hepatoduodenal ligament and/or around the head of the pancreas. The incidence of invasion of the lymphatic systems or the nervous system in Type III and IV were higher than in Type I or II, although the differences were not statistically significant. According to the International Union Against Cancer (UICC) classification, two patients were at stage IA, five were at stage IB, one was at stage IIA, four were at stage IIB, and three were at stage III. The 5-year survival rate of the 15 patients who underwent resection was $40 \%$, and median survival was 2.4 years (Fig. 3). With the exception of one patient who survived tumor-free for 6 years and died of an unrelated cause, all deaths during follow-up were due to cancer recurrence. Survival was significantly longer in patients with Type I than in those with Type IV $(P<0.05)$. Although there were no significant differences in survival rate among patients with Type II, III, and IV cystic duct carcinoma, respectively, patients with Type IV cystic duct carcinoma had the worst outcome (Fig. 4). 
Table 1 Clinical futures of 15 patients with primary cystic duct carcinoma

\begin{tabular}{|c|c|c|c|c|c|c|c|c|}
\hline \multirow{2}{*}{$\begin{array}{l}\text { Age (years)/ } \\
\text { gender }\end{array}$} & \multirow[t]{2}{*}{ Jaundice } & \multirow{2}{*}{$\begin{array}{l}\text { Hydropic } \\
\text { GB }\end{array}$} & \multirow[t]{2}{*}{ Cholelithiasis } & \multicolumn{2}{|c|}{ Findings of cholangiography } & \multirow{2}{*}{$\begin{array}{l}\text { Preoperative } \\
\text { diagnosis }\end{array}$} & \multirow{2}{*}{$\begin{array}{l}\text { Intraoperative } \\
\text { diagnosis }\end{array}$} & \multirow[t]{2}{*}{ Subtype } \\
\hline & & & & $\begin{array}{l}\text { Cystic } \\
\text { duct }\end{array}$ & $\begin{array}{l}\text { Extrahepatic bile } \\
\text { duct }\end{array}$ & & & \\
\hline $57 / \mathrm{M}$ & - & + & - & Obstruct & Normal & Cholecystitis & $\begin{array}{l}\text { Primary CD } \\
\text { carcinoma }\end{array}$ & I \\
\hline $81 / \mathrm{M}$ & - & + & + & NE & $\mathrm{NE}$ & Cholecystitis & Cholecystitis $^{\mathrm{b}}$ & I \\
\hline $79 / \mathrm{F}$ & - & + & + & NE & NE & Cholecystitis & Carcinoma of GB & II \\
\hline $64 / \mathrm{M}$ & - & + & - & NE & NE & Cholecystitis & Cholecystitis $^{\mathrm{b}}$ & II \\
\hline $71 / \mathrm{M}$ & - & + & - & Obstruct & Normal & Carcinoma of CD & $\begin{array}{r}\text { Primary CD } \\
\text { carcinoma }\end{array}$ & II \\
\hline $62 / \mathrm{F}$ & + & + & - & Obstruct & Irregular & Carcinoma of GB & Carcinoma of GB & II \\
\hline $65 / \mathrm{M}$ & + & + & + & Not detected & Narrowing & Carcinoma of BD & Carcinoma of $\mathrm{BD}$ & III \\
\hline $62 / \mathrm{F}$ & + & - & - & Not detected & Narrowing & Carcinoma of BD & $\begin{array}{l}\text { Primary CD } \\
\text { carcinoma }\end{array}$ & III \\
\hline $62 / \mathrm{F}$ & + & + & - & Not detected & Narrowing & Carcinoma of CD & $\begin{array}{r}\text { Primary CD } \\
\text { carcinoma }\end{array}$ & III \\
\hline 69/M & + & + & - & Not detected & Narrowing & Carcinoma of BD & $\begin{array}{l}\text { Primary CD } \\
\text { carcinoma }\end{array}$ & III \\
\hline $80 / \mathrm{M}$ & + & + & - & Not detected & Narrowing & Carcinoma of CD & $\begin{array}{r}\text { Primary CD } \\
\text { carcinoma }\end{array}$ & III \\
\hline $62 / \mathrm{M}$ & + & + & - & Not detected & Obstruct & Carcinoma of BD & Carcinoma of $\mathrm{BD}$ & IV \\
\hline 68/M & + & + & - & Not detected & Obstruct & Carcinoma of BD & Carcinoma of $\mathrm{BD}$ & IV \\
\hline $71 / \mathrm{F}$ & + & + & - & Not detected & Obstruct & Carcinoma of BD & Carcinoma of BD & IV \\
\hline 74/M & + & + & - & Not detected & Narrowing & Carcinoma of BD & $\begin{array}{l}\text { Primary CD } \\
\text { carcinoma }\end{array}$ & IV \\
\hline
\end{tabular}

$M$ Male; $F$ female; $N E$ not examined; $G B$ gallbladder; $C D$ cystic duct; $B D$ extrahepatic bile duct

a Subtype: distribution of tumor (see Fig. 1)

b Two patients initially underwent laparotomy for acute cholecystitis at another institution

Comparison of clinico-histological findings between cystic duct carcinoma and gallbladder carcinoma or extrahepatic bile duct carcinoma

In our series, the incidence of cystic duct carcinoma was $6.6 \%$ among all malignant biliary tumors. Comparison of the clinicopathological findings between gallbladder carcinoma and bile duct carcinoma showed that patients with gallbladder carcinoma showed a female predominance, a high frequency of hepatic infiltration, and a low frequency of perineural infiltration compared with patients who had bile duct carcinoma $(P<0.05)$. Comparison between cystic duct carcinoma and gallbladder carcinoma showed a significantly higher incidence of perineural infiltration $(P=0.014)$ and a significantly lower incidence of hepatic infiltration $(P=0.004)$ in primary cystic duct carcinoma (Table 4). There was no significant difference in clinicopathologic features between cystic duct carcinoma and bile duct carcinoma except for the frequency of hepatic infiltration.
Table 2 Surgical procedures for primary carcinoma of the cystic duct

\begin{tabular}{lllll}
\hline Operation & \multicolumn{3}{l}{ Subtype $^{\mathrm{a}}$} \\
\cline { 2 - 5 } & I & II & III & IV \\
\hline $\begin{array}{l}\text { Cholecystectomy with extrahepatic } \\
\text { bile duct resection }\end{array}$ & 2 & & & \\
$\begin{array}{l}\text { Cholecystectomy without extrahepatic } \\
\text { bile duct resection }\end{array}$ & 1 & & \\
$\begin{array}{l}\text { Extrahepatic bile duct resection } \\
\quad \text { with partial liver resection }\end{array}$ & 1 & 1 & \\
$\begin{array}{l}\text { Pancreatoduodenectomy } \\
\text { Extended right hepatectomy }\end{array}$ & 2 & 1 & \\
Hepatopancreatoduodenectomy & & 3 & 3 \\
\hline
\end{tabular}

a Subtype: distribution of tumor (see Fig. 1)

\section{Discussion}

Carcinoma of the cystic duct is a rare condition. When Farrar [1] reported his case in 1951, he found that very few 
Table 3 Histopathological futures of 15 patients with primary cystic duct carcinoma

\begin{tabular}{|c|c|c|c|c|c|c|c|c|c|}
\hline Subtypes $^{\mathrm{a}}$ & $\begin{array}{l}\text { Macroscopic } \\
\text { types }\end{array}$ & $\begin{array}{l}\text { Histological } \\
\text { type }^{\text {b }}\end{array}$ & $\begin{array}{l}\text { Depth of } \\
\text { tumor } \\
\text { invasion }^{c}\end{array}$ & $\begin{array}{l}\text { Growth } \\
\text { patterns }\end{array}$ & $\begin{array}{l}\text { Invasion of the } \\
\text { lymphatic } \\
\text { system }\end{array}$ & $\begin{array}{l}\text { Invasion of the } \\
\text { venous system }\end{array}$ & $\begin{array}{l}\text { Invasion of the } \\
\text { nervous system }\end{array}$ & $\begin{array}{l}\text { Lymph node } \\
\text { involvement }\end{array}$ & $\begin{array}{l}\text { Hepatic } \\
\text { infiltration }\end{array}$ \\
\hline I & Superficial type & Tub well & $\mathrm{fm}$ & $\mathrm{INF} \alpha$ & Absent & Absent & Absent & Absent & Absent \\
\hline I & Nodular type & Pap & se & $\mathrm{INF} \beta$ & Present & Present & Present & Present & Absent \\
\hline II & Nodular type & Pap & ss & $\mathrm{INF} \alpha$ & Absent & Absent & Absent & Absent & Absent \\
\hline II & Papillary type & Tub mod & se & $\operatorname{INF} \beta$ & Present & Present & Present & Present & Present \\
\hline II & Papillary type & Tub por & se & $\mathrm{INF} \alpha$ & Present & Absent & Absent & Absent & Absent \\
\hline II & Flat type & Tub por & si & $\mathrm{INF} \gamma$ & Present & Present & Present & Absent & Absent \\
\hline III & Nodular type & Pap & $\mathrm{fm}$ & INF $\beta$ & Absent & Absent & Absent & Absent & Absent \\
\hline III & Nodular type & Tub well & ss & $\mathrm{INF} \gamma$ & Present & Present & Present & Absent & Present \\
\hline III & Nodular type & Tub well & ss & $\mathrm{INF} \gamma$ & Present & Present & Present & Absent & Absent \\
\hline III & Nodular type & Tub por & ss & $\mathrm{INF} \gamma$ & Present & Absent & Present & Absent & Absent \\
\hline III & Nodular type & Tub por & ss & INF $\gamma$ & Present & Present & Present & Absent & Absent \\
\hline IV & Nodular type & Tub well & ss & $\operatorname{INF} \beta$ & Present & Present & Present & Present & Absent \\
\hline IV & Nodular type & Tub well & ss & $\mathrm{INF} \beta$ & Present & Present & Present & Present & Absent \\
\hline IV & Nodular type & Tub well & ss & $\mathrm{INF} \beta$ & Present & Present & Present & Present & Absent \\
\hline IV & Nodular type & Tub por & si & $\mathrm{INF} \beta$ & Present & Present & Present & Absent & Present \\
\hline
\end{tabular}

a Subtype: distribution of tumor (see Fig. 1)

${ }^{\text {b }}$ pap, Papillary adenocarcinoma; tub well, tubular adenocarcinoma (well-differentiated type); tub mod, tubular adenocarcinoma (moderately differentiated type); tub por, tubular adenocarcinoma (poorly differentiated type)

${ }^{c} \mathrm{~m}$, Invasion limited to the mucosa; fm, Invasion limited to the fibromuscular layer; ss, invasion limited to the subserosa; se, invasion of the serosa; si, invasion beyond the serosa

${ }^{d}$ INF $\alpha$, An expanding growth pattern with a distinct border from the surrounding tissue; INF $\beta$, an intermediate growth pattern between the INF $\beta$ and INF $\gamma ; \mathrm{INF} \gamma$, an infiltrating growth pattern with an indistinct border from the surrounding tissue

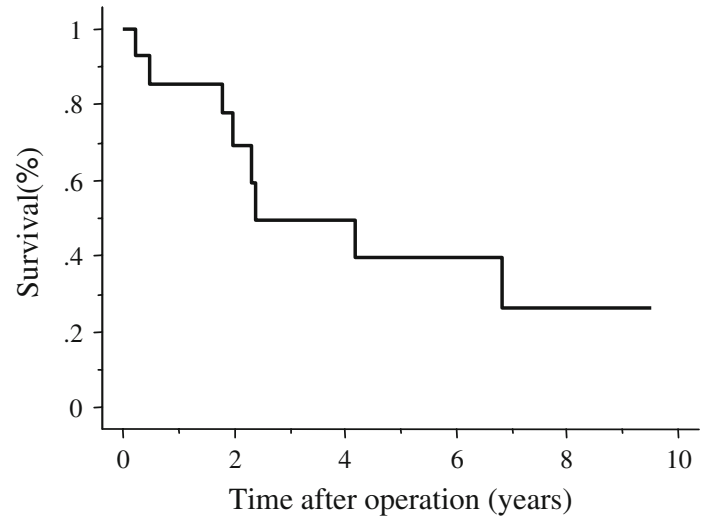

Fig. 3 Overall survival rate of the 15 patients with primary cystic duct carcinoma. 1- and 5-year survival rate $=86$ and $40 \%$, respectively

others had been described in the literature, and none of these were indisputable cases of primary carcinoma of the cystic duct. He therefore proposed criteria for the diagnosis of primary carcinoma of the cystic duct: (1) growth restricted to the cystic duct; (2) absence of neoplasia in the gallbladder, hepatic ducts, or common bile duct; (3) histological confirmation of carcinoma cells in the mass.

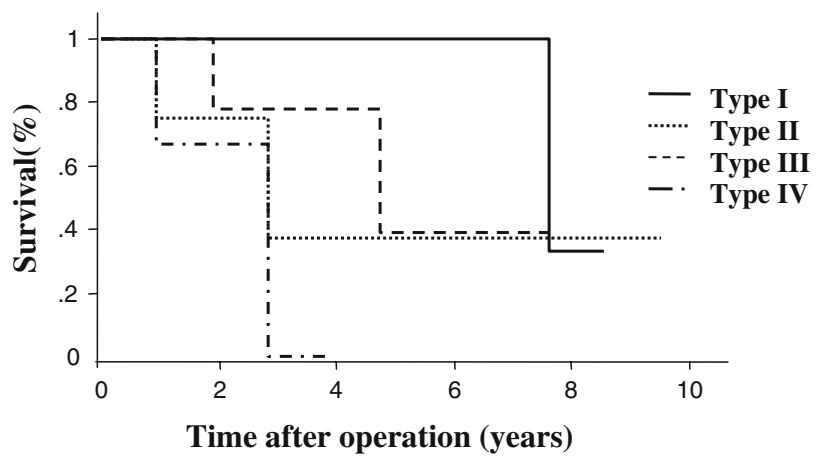

Fig. 4 Patient survival stratified according to the types of primary cystic duct carcinoma on the basis of the extent of tumor spread. Median survival rates of Types I, II, III and IV were 7.4, 2.5, 4.5, and 2.1 years, respectively. Survival was significantly longer in patients with Type I than in those with type IV $(P<0.05)$. Although there were no significant differences in survival rate among patients with Type II, III and IV cystic duct carcinoma, those with Type IV cystic duct carcinoma had the worst outcome

However, Farrar's strict definition of cystic duct carcinoma causes several problems in clinical practice. If the definition is applied strictly, a "restricted" cystic duct carcinoma becomes a "non-cystic duct carcinoma" once it advances 
Table 4 Comparison with cystic duct carcinoma and gallbladder carcinoma or extrahepatic bile duct carcinoma in clinicohistological findings

\begin{tabular}{|c|c|c|c|c|}
\hline Clinico-histological parameters & $\begin{array}{l}\text { Primary carcinoma } \\
\text { of cystic duct }\end{array}$ & $\begin{array}{l}\text { Carcinoma of the } \\
\text { gallbladder }\end{array}$ & $\begin{array}{l}\text { Carcinoma of the } \\
\text { upper bile duct }\end{array}$ & $\begin{array}{l}\text { Carcinoma of the } \\
\text { middle-lower bile duct }\end{array}$ \\
\hline Number of patients & $n=15$ & $n=52$ & $n=112$ & $n=49$ \\
\hline Median age (years) & $67.8 \pm 7.9$ & $66.2 \pm 11.4$ & $67.6 \pm 8.3$ & $68.9 \pm 7.6$ \\
\hline Range (years) & $57-81$ & $27-84$ & $39-84$ & $50-83$ \\
\hline Male:female (male percentage) & $10: 5(66.7 \%)$ & $23: 29(44.2 \%)^{\mathrm{b}}$ & $80: 32(71.4 \%)^{\mathrm{b}}$ & $41: 8(83.7 \%)^{\mathrm{b}}$ \\
\hline \multicolumn{5}{|l|}{ Histological type } \\
\hline $\begin{array}{l}\text { Papillary and well-differentiated } \\
\text { adenocarcinoma }\end{array}$ & $9(60.0 \%)$ & $26(50.0 \%)$ & $62(55.4 \%)$ & $27(55.1 \%)$ \\
\hline $\begin{array}{l}\text { Moderately and poorly differentiated } \\
\text { adenocarcinoma }\end{array}$ & $6(40.0 \%)$ & $20(38.5 \%)$ & $49(43.8 \%)$ & $19(38.8 \%)$ \\
\hline Other & $0(\%)$ & $6(11.5 \%)$ & $2(1.8 \%)$ & $3(6.1 \%)$ \\
\hline \multicolumn{5}{|l|}{ Depth of invasion } \\
\hline To fibromuscular layer/muscle layer & $2(13.3 \%)$ & $7(13.5 \%)$ & $14(12.5 \%)$ & $6(12.2 \%)$ \\
\hline Subserosa & $8(53.3 \%)$ & $19(36.5 \%)$ & $76(67.9 \%)$ & $28(57.1 \%)$ \\
\hline Beyond serosa & $5(33.3 \%)$ & $26(50.0 \%)^{\mathrm{b}}$ & $22(20.0 \%)^{\mathrm{b}}$ & $15(30.6 \%)$ \\
\hline \multicolumn{5}{|l|}{ Lymphatic invasion } \\
\hline Present & $12(80.0 \%)$ & $34(65.4 \%)^{\mathrm{b}}$ & $98(87.5 \%)^{\mathrm{b}}$ & $43(87.8 \%)^{b}$ \\
\hline \multicolumn{5}{|l|}{ Venous invasion } \\
\hline Present & $10(66.7 \%)$ & $36(69.2 \%)$ & $83(74.1 \%)$ & $37(76.3 \%)$ \\
\hline \multicolumn{5}{|l|}{ Perineural invasion } \\
\hline Present & $11(73.3 \%)^{\mathrm{a}}$ & $24(46.1 \%)^{\mathrm{a}, \mathrm{b}}$ & $96(85.7 \%)^{\mathrm{b}}$ & $37(75.5 \%)^{\mathrm{b}}$ \\
\hline \multicolumn{5}{|l|}{ Lymph node involvement } \\
\hline Present & $5(33.3 \%)$ & $20(38.5 \%)$ & $53(47.3 \%)$ & $17(34.7 \%)$ \\
\hline \multicolumn{5}{|l|}{ Infiltrating type of tumor progression } \\
\hline Invasive type & $12(80.0 \%)$ & $39(75.0 \%)^{\mathrm{b}}$ & $101(90.2 \%)^{\mathrm{b}}$ & $46(93.9 \%)^{b}$ \\
\hline \multicolumn{5}{|l|}{ Hepatic infiltration } \\
\hline Present & $3(20.0 \%)^{\mathrm{a}}$ & $32(61.5 \%)^{\mathrm{a}, \mathrm{b}}$ & $49(43.8 \%)^{\mathrm{b}}$ & $0(0 \%)^{\mathrm{b}}$ \\
\hline
\end{tabular}

${ }^{a}$ A probability value was less than 0.05 between cystic duct carcinomas and gallbladder carcinomas

b A probability value was less than 0.05 between bile duct carcinomas and gallbladder carcinomas

beyond the cystic duct. As a result, in some patients it is actually very difficult to decide whether the tumor should be considered as "restricted to the cystic duct". Given these problems, we have been using the alternative definition based on the location of the tumor center. It should be emphasized here that cases where the tumor extends into the hepatic bile duct, common bile duct or gallbladder would not be diagnosed as primary carcinoma of the cystic duct by Farrar's strict criteria. In advanced tumors that have extensively invaded the surrounding structures, the site of origin is not obvious at first glance, but histological examination of serial sections of the resected specimens will show the center of the tumor, thus allowing a diagnosis of cystic duct carcinoma. From the same viewpoint, Ozden et al. [10] reported 31 patients with cystic duct carcinoma. Although a previous report summarized approximately 30 cases of primary cystic duct carcinoma that met Farrar's criteria [3], the rarity of reports of primary cystic duct carcinoma may be due to the strictness of those criteria; consequently, primary cystic duct carcinoma may be more common than has been assumed $[3,6,10]$. Farrar's criteria also make allowance for concomitant obstructive jaundice $[11,12]$, although this cannot occur in cases of "restricted" cystic duct carcinoma. To overcome this obscurity, we have proposed four clinical types based on the extent of tumor spread: Type I, the tumor is restricted wholly within the cystic duct; Type II, the tumor extends into the lumen of the gallbladder; Type III, the tumor extends to the common hepatic duct or the common bile duct; Type IV, the tumor extends to both the gallbladder and bile duct. This proposed definition may remove some of the confusion currently associated with the definition of cystic duct carcinoma $[11,12]$. It is understandable that obstructive jaundice does not occur in Type I cystic duct carcinoma, whereas it does occur in Type III or IV cystic duct carcinoma. 
There have been reports that cystic duct carcinoma accounts for 2.6\% [13] and 3.3\% [14] of all carcinomas of the bile duct and 1.5\% [15] of all carcinomas of the gallbladder. Although the frequency of cystic duct carcinoma, including advanced tumors, has not been described in previous reports $[10,16]$, in our series, the incidence of cystic duct carcinoma was $6.6 \%$ of all malignant biliary tumors, $22 \%$ of gallbladder carcinomas, and $8.5 \%$ of extrahepatic bile duct carcinomas, while that of "restricted" cystic duct carcinoma was $0.9 \%$ of all malignant biliary tumors.

"Classical" gallbladder carcinoma occurs predominantly in women, with the gender predilection ranging from 1:2 to $1: 3$ [17]. In our series, the male:female ratio of patients with cystic duct carcinoma was $2: 1$, corresponding to the ratio of 1.9:1 reported in an earlier publication [2]. Jaundice was present in $67 \%$ of the patients in our series; Ozden indicated that $90 \%$ of his patients with cystic duct carcinoma had increased serum total bilirubin levels [10]. Hydrops is a characteristic finding in patients with cystic duct carcinoma $[10,18]$ and was present in $93 \%$ of the patients in our series. This condition is probably due to the obstruction of the narrow cystic duct by the tumor in the early stage. In our study, it was difficult to diagnose the primary carcinoma of the cystic duct during the very early stage; however, MDCT increased diagnostic sensitivity to $75 \%$.

Although the earliest operative procedures were limited to cholecystectomy with bile duct resection and additional lymph node dissection [2,3], in our series, ten of the 15 patients underwent aggressive radical surgery (e.g., pancreatoduodenectomy or extended right hepatectomy). Because "advanced" cystic duct carcinoma easily invades the hepatic bile duct, common bile duct, right hepatic artery or portal vein, radical surgery is required for complete macroscopic removal of the cancer.

Histological studies revealed that there was a high frequency of perineural infiltration of cancer in patients with cystic duct carcinoma, similar to the case of upper or middle/lower bile duct carcinoma. The neural network in the hepatoduodenal ligament is very complex. Although it has not been well described, it is known to contain rich autonomic nerve networks, especially around the hepatic artery and portal vein. Perineural invasion has been identified by several authors as a very important risk factor in patients with extrahepatic bile duct carcinoma [19-22]. To our knowledge, the incidence of perineural invasion is higher in extrahepatic bile duct carcinoma (85-93\%) than in gallbladder carcinoma (24-72\%) [20-28]. While carcinoma of the cystic duct is included in the category of extrahepatic bile duct carcinoma in the American Joint Committee on Cancer (AJCC) Cancer Staging Manual [29], primary carcinoma of the cystic duct is classified as gallbladder carcinoma by the Japanese Society of Biliary
Surgery [4]. Our findings indicate that its clinical features differ from those of gallbladder carcinoma (e.g., in terms of male to female ratio, incidence of associated gallstones, and frequency of perineural invasion). However, the number of patients in our series with "advanced" cystic duct carcinoma was too limited to allow conclusions to be drawn about its characteristics. Moreover, because we calculated the survival rate on a low sample size, there were constraints to any emphasis on the survival rate. Further studies using a large patient cohort should be undertaken to adequately clarify the operative procedure for "advanced" cystic duct carcinoma and prognosis.

Our modified definition of carcinoma of the cystic duct, involving four proposed subtypes based on the extent of tumor spread, may avoid the problems associated with Farrar's criteria when clinicians are faced with classifying the characteristics of cystic duct carcinoma. Preoperative preparation, operative procedure, and histological features differ among these four groups. For example, Types I and II have no associated jaundice, whereas Type III or IV may cause obstructive jaundice. If a gallbladder stone or tumor cannot be found in the hydropic gallbladder resected by laparoscopic cholecystectomy, Type I or III cystic duct carcinoma should be considered in the differential diagnosis. Furthermore, bile duct resection may be required in patients with Type III or IV, but it is unclear whether the bile duct should be preserved in patients with Type I or II. It is controversial whether bile duct resection should be performed for patients with locally advanced gallbladder carcinoma without bile duct infiltration [30, 31]. As well as the Bithmuth criteria [32] based on the location of hilar bile duct carcinoma, which is widely used by surgeons $[8,33]$, a classification of cystic duct carcinoma that includes the "advanced" form may facilitate surgical decision-making, although the number of cystic duct carcinoma patients is very infrequent.

In conclusion, we have proposed a modified definition of primary cystic duct carcinoma with four subtypes based on the extent of tumor spread. Although cystic duct carcinoma is treated as gallbladder carcinoma by the Japanese criteria [7], the data we present here show that a high frequency of perineural infiltration and a low frequency of hepatic infiltration result in cystic duct carcinoma being a distinct entity from gallbladder carcinoma. From a prognostic viewpoint, even if advanced cystic duct carcinoma has invaded the surrounding structures extensively, radical surgery may improve the outcome.

\section{References}

1. Farrar DA. Carcinoma of the cystic duct. Br J Surg. 1951;39:183-5.

2. Chijiiwa K, Torisu M. Primary carcinoma of the cystic duct. J Clin Gastroenterol. 1993;16:309-13. 
3. Sato M, Watanabe Y, Kikkawa H, Kohtani T, Suzuki H, Nezu K, et al. Carcinoma of the cystic duct associated with pancreaticobiliary maljunction. J Gastroenterol. 2001;36:276-80.

4. Siewert JR, Stein HJ. Adenocarcinoma of the gastroesophageal junction. Classification, pathology and extent of resection. Dis Esophagus. 1996;9:173-92.

5. Siewert JR, Stein HJ. Classification of adenocarcinoma of the oesophagogastric junction. Br J Surg. 1998;85:1457-9.

6. Ohtani T, Shirai Y, Tsukada K, Hatakeyama K, Muto T. The association between extrahepatic biliary carcinoma and the junction of the cystic duct and the biliary tree. Eur J Surg. 1994;160:37-40.

7. Japanese Society of Biliary Surgery, editor. General rules for surgical and pathological studies on cancer of biliary tract. 5th edn. Tokyo: Kimbara Press; 2002.

8. Kawasaki S, Imamura H, Kobayashi A, Noike T, Miwa S, Miyagawa S. Results of surgical resection for patients with hilar bile duct cancer: application of extended hepatectomy after biliary drainage and hemihepatic portal vein embolization. Ann Surg. 2003;238:84-92.

9. International Union against Cancer (UICC). TNM classification of malignant tumors. 5th edn. New York: Wiley-Liss; 1997.

10. Ozden I, Kamiya J, Nagino M, Uesaka K, Oda K, Sano T, et al. Cystic duct carcinoma: a proposal for a new "working definition". Langenbecks Arch Surg. 2003;387:337-42.

11. Holzinger F, Schilling M, Z'graggen K, Stain S, Baer HU. Carcinoma of the cystic duct leading to obstructive jaundice. A case report and review of the literature. Dig Surg. 1998;15:273-8.

12. De Waele B, Beaurang J, Smekens L, Pipeleers-Marichal M. Carcinoma of cystic duct leading to obstructive jaundice. Dig Dis Sci. 1984;29:865-7.

13. Glenn F, Hill MR Jr. Extrahepatic biliary tract cancer. Cancer. 1955;8:1218-25.

14. Neibling HA, Dockerty MB, Waugh JM. Carcinoma of the extrahepatic bile ducts. Surg Gynecol Obstet. 1949;89:429-38.

15. Vaittinen E. Carcinoma of the gallbladder. A study of 390 cases diagnosed in Finland 1953-1967. Ann Chir Gynaecol Fenn. 1970;59:7-81.

16. Kondo S, Nimura Y, Kamiya J, Nagino M, Kanai M, Uesaka K, et al. Mode of tumor spread and surgical strategy in gallbladder carcinoma. Langenbecks Arch Surg. 2002;387:222-8.

17. Pitt SA. Biliary tract. In: Townsend CM, Beauchamp RD, Evers BM, Mattox KL, editors. Sabiston textbook of surgery. Philadelphia: Saunders; 2001. p. 1076-111.

18. Pack GT, Teng PK. Carcinoma of cystic duct leading to hydrops of gallbladder. JAMA. 1968;8(203):153-4.

19. Bhuiya MR, Nimura Y, Kamiya J, Kondo S, Fukata S, Hayakawa $\mathrm{N}$, et al. Clinicopathological studies on perineural invasion of bile duct carcinoma. Ann Surg. 1992;215:344-9.
20. Ogura Y, Takahashi K, Tabata M, Mizumoto R. Clinicopathological study on carcinoma of the extrahepatic bile duct with special focus on cancer invasion on the surgical margins. World J Surg. 1994;18:778-84.

21. Seyama Y, Kubota K, Sano K, Noie T, Takayama T, Kosuge T, et al. Long-term outcome of extended hemihepatectomy for hilar bile duct cancer with no mortality and high survival rate. Ann Surg. 2003;238:73-83.

22. Nagakawa T, Mori K, Nakano T, Kadoya M, Kobayashi H, Akiyama T, et al. Perineural invasion of carcinoma of the pancreas and biliary tract. Br J Surg. 1993;80:619-21.

23. Nimura Y, Kamiya J, Kondo S, Nagino M, Uesaka K, Oda K, et al. Aggressive preoperative management and extended surgery for hilar cholangiocarcinoma: Nagoya experience. J Hepatobiliary Pancreat Surg. 2000;7:155-62.

24. Yamaguchi R, Nagino M, Oda K, Kamiya J, Uesaka K, Nimura Y. Perineural invasion has a negative impact on survival of patients with gallbladder carcinoma. Br J Surg. 2002;89:1130-6.

25. He P, Shi JS, Chen WK, Wang ZR, Ren H, Li H. Multivariate statistical analysis of clinicopathologic factors influencing survival of patients with bile duct carcinoma. World J Gastroenterol. 2002;8:943-6.

26. Fahim RB, McDonald JR, Richards JC, Ferris DO. Carcinoma of the gallbladder: a study of its modes of spread. Ann Surg. 1962;156:114-24.

27. Chijiiwa K, Yamaguchi K, Tanaka M. Clinicopathologic differences between long-term and short-term postoperative survivors with advanced gallbladder carcinoma. World J Surg. 1997;21:98102 .

28. Kaneoka Y, Yamaguchi A, Isogai M, Harada T, Suzuki M. Hepatoduodenal ligament invasion by gallbladder carcinoma: histologic patterns and surgical recommendation. World J Surg. 2003;27:260-5.

29. American Joint Committee on Cancer. AJCC cancer staging manual. 6th ed. Springer: New York, NY; 2002. p. 145-50.

30. Kosuge T, Sano K, Shimada K, Yamamoto J, Yamasaki S, Makuuchi M. Should the bile duct be preserved or removed in radical surgery for gallbladder cancer? Hepatogastroenterology. 1999;46:2133-7.

31. Shimizu Y, Ohtsuka M, Ito H, Kimura F, Shimizu H, Togawa A, et al. Should the extrahepatic bile duct be resected for locally advanced gallbladder cancer? Surgery. 2004;136:1012-7.

32. Bismuth $\mathrm{H}$, Corlette MB. Intrahepatic cholangioenteric anastomosis in carcinoma of the hilus of the liver. Surg Gynecol Obstet. 1975;140:170-8.

33. Bismuth $H$, Nakache R, Diamond T. Management strategies in resection for hilar cholangiocarcinoma. Ann Surg. 1992;215:31-8. 